\title{
KNOWLEDGE AND UNDERSTANDING OF MEDICAL STUDENTS ABOUT RADIOTHERAPY AND PALLIATIVE CARE
}

Dr. Abeer Nisar Arain', Dr. Zunaira Abdul Ghaffar², Dr. Naveed-ur-Rehman ${ }^{3}$, Dr. M. N. Siddiqi ${ }^{4}$, Dr. Raza Rehman ${ }^{5}$

1. MBBS

University of Oklahoma Health Sciences Centre

800 N.E. $10^{\text {th }}$ Street, OKCC L100

2. MBBS

Dow University of Health Sciences, Karac 3. FCPS (Medicine)

Assistant Professor

Independent Medical College,

Faisalabad

4. Sindh Institute of Urology and Transplantation, Sindh

5. MD

HOD of the Psychiatry Department,

$\mathrm{CHK}$

Professor at Dow University of

Health Sciences, Karachi

Correspondence Address:

Dr. Zunaira Abdul Ghaffar

F18, 316 Tahseen Plaza,

Garden West, Karachi-74550,

Pakistan

zunairag@hotmail.com

Article received on:

28/10/2013

Accepted for Publication

30/03/2014

Received after proof reading:

$11 / 04 / 2014$

\section{INTRODUCTION}

Cancer is the group of diseases characterized by uncontrolled growth and spread of abnormal cells. If the dissemination is not controlled, it can result in death". The global burden of cancer continues to increase largely because of aging and growth of the world population alongside an increasing adoption of cancer causing behavior particularly smoking in economically developing countries ${ }^{2}$. Issued from GLOBOCAN 2008 estimates, about 12.7 million cancer cases and 7.6 million cancer deaths are estimated to have occurred in 2008. $56 \%$ cases and $64 \%$ of deaths occurred in economically developing countries ${ }^{3}$. Moreover World Health Organization (WHO) has projected an annual cancer incidence rate of 20 million per year by the year $2020^{4}$. Therefore it has become
ABSTRACT... Objective: To assess the knowledge of undergraduate medical students about radiotherapy, cancer and palliative care in cancer. Method: A descriptive study to assess the knowledge of radiotherapy, cancer and palliative care is conducted among undergraduate edical students of Dow Medical College. 300 students from each batch of fourth and final year ( general knowlo re thirds $(60 \%)$ of participants. The knowledge regarding cancer prevention prevailed around undergraduate curriculum of MBBS, and it should be mandatory for all the students. Oncology rotations should be constructed where the principles of radiotherapy and palliative care can be Key words: $\quad$ Radiotherapy, Palliative care, Cancer information, medical students.

Article Citation: Arain AN, Ghaffar ZA, Naveed-ur-Rehman, Siddiqui MN, Rehman R. Knowledge and understanding of medical studnets about radiotherapy and palliative care. Professional Med J 2014;21(2): 325-332.

very important for undergraduate medical students to have a thorough knowledge of cancer, its prevalence and different types of treatment offered to cancer patients.

Acquiring proper knowledge about cancer prevention has also become very crucial for medical students all over the world. According to American cancer society, in 2010, about 171,000 cancer deaths occurred due to tobacco use. All the cancers caused by cigarette smoking and alcohol are preventable. Scientific evidence suggests that about one-third of the 569,490 cancer deaths in 2010 were due to obesity, physical inactivity and poor nutrition thus could also be prevented ${ }^{5}$. Among all the cancers, Breast cancer is the most frequently diagnosed and the 
leading cause of death among females accounting for $23 \%$ total cases and $14 \%$ cancer deaths, Lung cancer is the leading cancer in males comprising $17 \%$ of new cases and $23 \%$ deaths globally $^{6}$. There are various modalities of cancer treatment. It is treated by surgery, radiation, chemotherapy, hormonal, biological and targeted therapy. Among these therapies, radiotherapy is estimated to be a necessary component of cancer care in approximately $52 \%$ of cases ${ }^{7}$. The intent of radiotherapy treatments may be cancer cure, prevention of relapse or relief from cancer symptoms and radiotherapy maybe the only treatment or used in conjunction with surgery/ or chemotherapy ${ }^{8}$. It uses high energy radiation in the form of $x$-rays or gamma rays delivered by the machine outside the body (teletherapy) or may come from radioactive material placed inside body near cancer cells (brachytherapy) ${ }^{8}$.

The term palliative care refers to the specialized area in health care that focuses on relieving and preventing the suffering of patients. It is appropriate for patients in all disease stages, including those undergoing treatment for curable illnesses and those living with chronic diseases, as well as patients who are close to the end of life ${ }^{9}$. Although the concept of palliative care is not new, most physicians are accustomed to concentrate on trying to cure patients. Treatment for the alleviation of symptoms were viewed as hazardous and seen as inviting addiction and unwanted side effects.

Surprisingly, there is little effort to improve undergraduate cancer education to cope with the new disease trend. Due to lack of knowledge about cancer, early detection of cases requiring radiotherapy and oncology interventions are delayed. There is also an almost nonexistence of palliative care input in undergraduate medical courses in some Universities ${ }^{10}$.

The aim of this study is to find out the knowledge of radiation therapy, cancer and palliation treatment among the undergraduate medical students.

\section{METHODS}

We replicated the study conducted by $\mathrm{Dr}$ BM Biswal in Sains University Malaysia. We contacted him and he provided the questionnaire for this study.

We conducted an observational study to assess the knowledge of radiotherapy, cancer and palliative care among undergraduate medical students. Study was conducted in Dow medical college, Dow University of Health Sciences. Dow medical college is one of the oldest medical schools in Pakistan, since 2003, It has become the constituent college of Dow university of health sciences, a public sector university that has produced a large number of well-trained doctors, who are now spread all over the world, proving themselves as authorities in different fields of medicine. The educational curriculum of college consists of lectures, problem based learning (PBL) discussions, evidence based learning and the examination pattern consists of best choice questions (bcq's) and structured practical exams called OSPE and OSCE.

All the final year and fourth year undergraduate medical students of Dow medical college, who are currently enrolled, were considered in the study. There are about 300 students in each batch. All of the students were given the questionnaire. The students were asked 27 questions mentioned in the questionnaire. There were 5 questions from each topic including radiotherapy, palliative care, cancer knowledge and cancer prevention. The remaining 7 questions were related to student's frequency to radiotherapy units, source of cancer information and teaching programs of radiotherapy in medical college. In the end of questionnaire, students were also asked about radiotherapy as the choice of career and participation in palliative care course during their undergraduate years. Ethical committee of Dow University of health sciences gave approval for this study. The objective and protocol of study was explained to all students and verbal consent was taken. 


\section{RESULTS}

From a total of 300 students, 246 students returned the questionnaires. Of these, approximately $50 \%$ were 4 th year medical students and $49 \%$ were final year students.

Table-I shows the data about knowledge of radiotherapy among undergraduate medical students. Approximately $41 \%$ of students correctly questions related to the knowledge about radiotherapy, breakdown of which is as follows: $68.3 \%$ students correctly answered the questions pertaining to the subjects included in radiotherapy. A mere $6.1 \%$ had an idea about the diseases that are best treated with radiotherapy, while $43.5 \%$ knew that skin cancer is completely cured with radiotherapy. $47.9 \%$ students knew about teletherapy, while $47.9 \%$ knew about brachytherapy.

Table-Il shows data regarding cancer treatment knowledge among students that averaged around $32 \%$. The knowledge about palliative care among the students was $55.7 \%$, whereas $39.8 \%$ students had knowledge about the WHO 3-step ladder approach. $75.2 \%$ students had no idea about the best alternative to analgesics in bone pain due to metastatic cancer whereas only $9.3 \%$ said they knew how to prescribe morphine tablets to cancer patients.

Table-III shows the knowledge present among the students regarding cancer, that was present in approximately two-thirds (60\%) of participants through following pertinent questions. First, a good percentage of students $(66.3 \%$ and $84.6 \%)$ knew about the common cancer in males and females respectively. Majority of students (92\%) knew lung cancer is definitely caused by smoking, but only a few students (29\%) knew about the peak age for cervical cancer and $72 \%$ had no idea about the 5-year cure rate of Hodgkin's lymphoma.

Table-IV shows the knowledge regarding cancer prevention (36.6\%). $63 \%$ students knew what is BSE in cancer prevention, and just $8.6 \%$ students said they can take a PAP smear independently. Finally, $36.6 \%$ of our students admitted that they had good knowledge regarding cancer prevention.

\begin{tabular}{|l|c|c|c|}
\hline \multicolumn{1}{|c|}{ Question that were asked } & Fourth year & Final year & Total \\
\hline Diseases treated by radiotherapy & $9 / 124(7.3 \%)$ & $6 / 122(4.9 \%)$ & $15 / 246(6.1 \%)$ \\
\hline Subjects included in radiotherapy & $70 / 124(56.5 \%)$ & $98 / 122(80.3 \%)$ & $168 / 246(68.3 \%)$ \\
\hline Meaning of teletherapy & $70 / 124(56.5 \%)$ & $52 / 122(42.6 \%)$ & $122 / 246(49.6 \%)$ \\
\hline Meaning of Brachytherapy & $54 / 124(43.5 \%)$ & $64 / 122(52.5 \%)$ & $118 / 246(47.9 \%)$ \\
\hline Cancer cured by radiotherapy & $28 / 124(22.6 \%)$ & $79 / 122(64.8 \%)$ & $107 / 246(43.5 \%)$ \\
\hline Questionnaire & Table-I. & & Final year \\
\hline What is palliative care & Fourth year & $79 / 122(64.8 \%)$ & $137 / 246(55.7 \%)$ \\
\hline WHO 3-step ladder approach & $58 / 124(46.8 \%)$ & $56 / 122(45.9 \%)$ & $98 / 246(39.8 \%)$ \\
\hline Best analgesia for bony metastasis pain & $42 / 124(33.8 \%)$ & $49 / 122(40.2 \%)$ & $61 / 246(24.8 \%)$ \\
\hline Knowledge about prescribing morphine & $12 / 124(9.7 \%)$ & $19 / 122(15.6 \%)$ & $23 / 246(9.3 \%)$ \\
\hline
\end{tabular}




\begin{tabular}{|l|r|r|r|}
\hline \multicolumn{1}{|c|}{ Questionnaire } & Fourth year & Final year & Total \\
\hline Common cancer in male & $83 / 124(66.9 \%)$ & $80 / 122(65.6 \%)$ & $163 / 246(66.3 \%)$ \\
\hline Common cancer in female & $108 / 124(87.1 \%)$ & $100 / 122(82.0 \%)$ & $208 / 246(84.6 \%)$ \\
\hline Cancer caused by smoking & $117 / 124(94.4 \%)$ & $109 / 122(89.3 \%)$ & $226 / 246(91.9 \%)$ \\
\hline 5 year cure rate Hodgkin's lymphoma & $12 / 124(9.7 \%)$ & $57 / 122(46.7 \%)$ & $69 / 246(28.0 \%)$ \\
\hline Peak age of cervical cancer & $40 / 124(32.3 \%)$ & $31 / 122(25.4 \%)$ & $71 / 246(28.9 \%)$ \\
\hline
\end{tabular}

\begin{tabular}{|l|c|c|c|}
\hline \multicolumn{1}{|c|}{ Questionnaire } & Fourth year & Final year & Total \\
\hline What is BSE & $71 / 124(57.3 \%)$ & $84 / 122(68.9 \%)$ & $155 / 246(63.0 \%)$ \\
\hline Independent use of pap smear & $9 / 124(7.3 \%)$ & $12 / 122(9.8 \%)$ & $21 / 246(8.6 \%)$ \\
\hline Knowledge of cancer prevention & Good knowledge 25/124 (20.2\%) & $65 / 122(53.3 \%)$ & $90 / 246(36.6 \%)$ \\
\hline
\end{tabular}

\section{DISCUSSION}

Cancer has become the leading cause of death in economically developed countries and second leading cause in developing countries ${ }^{11}$. The burden of cancer is increasing in developing countries due to aging of population as well as an adoption of cancer associated lifestyle choices including smoking, westernized diet and sedentary lifestyle. According to GLOBOCON 2008, about 12.7 million cancer cases and 7.6 million cancer deaths occurred in $2008^{12}$. Despite decrease in cancer related death rates in developed countries like USA, the number of cancer cases and deaths are projected to be more than double worldwide in the next $20-40$ years $^{13}$.

Cancer is mainly environmental disease with 9095\% cases occurring due to improper lifestyle and introduction of harmful environmental factors like pollution, chemical dyes etc. and only $5-10 \%$ of cancers are inherited ${ }^{14,15}$. And thus cancer is largely considered as a preventable disease. At present, we are equipped with many treatment and management options with primary ones including surgery, chemotherapy, radiation therapy and palliative care.

Therefore, it has become very important to increase cancer knowledge among medical students from their undergraduate level. And that is why we conducted this study to determine the level of understanding among medical students about radiation therapy and palliative care, which are two of the most critical specialties in cancer management. But the results of our study are not much different from the study conducted by BM. Biswal ${ }^{16}$ as it shows the poor understanding of radiotherapy and palliative care. The knowledge of radiotherapy among medical students ranged between $6.5 \%-68.3 \%$ with the mean of $40.9 \%$. Attendance to radiotherapy department of our student's shows huge difference when we compare the results with Dr. Biswal's study. In our study $54.3 \%$ students never attended radiation therapy department (10\% in Biswal's study) while $21.6 \%$ students visited radiotherapy department only once in their undergraduate training. The students showed good theoretical knowledge of cancer with the mean of $80.9 \%$ when asked about common cancers in male and female and cancers caused by smoking, while only $28.9 \%$ students had familiarity with the five year cure rate of Hodgkin's lymphoma, a cancer with rapidly increasing cure rate ${ }^{17}$ and just $28.9 \%$ students had correct information about peak age of cervical cancer, which is the third most common female cancer after skin and breast cancer $^{18}$. 
The current MBBS curriculum of Dow medical college consists of basic science subjects like pathology, pharmacology, microbiology, anatomy, physiology and biochemistry. The clinical subjects include Surgery, Medicine, Gynae and Obs, Pediatrics, Ophthalmology and Otolaryngology. There is hardly any theoretical class or practical on radiation therapy and palliative medicine in undergraduate curriculum. In a study conducted in UK ${ }^{19}, 27$ medical schools in UK are having a formal teaching program of palliative medicine. The hospice environment is playing an important role and majority of medical schools are using their local hospice as teaching resource. Another study from UK concluded that 26 radiotherapy departments and 21 medical oncology units have a regular commitment to undergraduate medical education ${ }^{20}$. In our setup, very often, an overview of these specialties is given to students during their teaching of radiology and there are no separate teachings for radiation therapy and palliative care. This may be one of the reasons that only $55.3 \%$ students acquainted the correct definition of palliative care and $36.6 \%$ students of fourth year and final year had an understanding of cancer prevention. In our questionnaire, students were also asked about accession of radiotherapy questions in their examination and about $40.7 \%$ students commented that they are occasionally asked. About $63.4 \%$ students who were included in our study regarded the inclusion of cancer knowledge as necessary in their undergraduate curriculum; many of them showed interest to have classes on cancer management and radiotherapy especially its role in cervical cancer and skin cancer.

World health organization established a three step ladder approach as a guideline for the treatment of cancer pain in $1986^{21}$. These three steps include the analgesic medications for mild, moderate and severe pain in cancer patients. The ladder is an effective guide to the palliative care physicians and assists them in selecting pain relieving medications for cancer patients. WHO recommends palliative care facility at all the health care center's $\mathrm{s}^{22-24}$. Therefore, wide circulation of WHO guidelines among doctors is necessary to have a clear improvement in the treatment of cancer pain. In our study, students were asked about the WHO step ladder approach, and only $39.8 \%$ students had awareness of 3-step ladder pain relief guidelines and just 9.3\% students had knowledge about recommending morphine. Lack of training in palliative medicine among Pakistani doctors is also highlighted in a study by S.Q Abbas $^{25}$. This deficiency of knowledge about cancer pain and palliative care can be due to more stress on curative treatment in our setup. Hence, there is a serious need of integrating palliative care courses in the existing curricula of undergraduate medical education to make palliative care an essential component of evidence based high quality care for the management of terminal illnesses.

In Pakistan, very few medical graduates are interested in taking Radiation therapy as their career choice. In our study, students were asked to choose their future specialty and many students did not show interest towards radiation oncology and only $5.0 \%$ selected radiotherapy as their first choice as to $38.5 \%$ students who chose internal medicine and $20.7 \%$ who selected general surgery as career choice. Such discrepancies are also noted in the studies conducted in India and Canada. In a study from India ${ }^{26}, 54 \%$ students felt that radiotherapy is still a low priority subject in the post graduate training and only $4 \%$ selected radiation therapy as their career choice. Majority of the students (70\%) anticipated that inadequate teaching of radiation therapy and lack of awareness among medical students are the main reasons behind this. Another survey was conducted in Canada and it showed that only $18 \%$ respondents chose radiation therapy as a choice for their residency training ${ }^{27}$. There can be several reasons behind this paucity of interest among medical graduates. The most important reasons are the lack of awareness about radiation therapy among undergraduates due to sub-optimal teaching of the subject in their curriculum and absence of radiation therapy posting during the 1year internship or house job of young doctors. It can also be due to uncertain job opportunities as few institutes in Pakistan offer post-graduation 
training in radiotherapy. Similarly there are few radiotherapy centers in Pakistan which are well equipped with modern radiation therapy machines. All these factors can be the cause of less number of fresh doctors choosing radiation oncology as career choice.

Our study highlighted many important points. The undergraduate students lack the basic and important knowledge about radiation therapy and palliative medicine despite of the increasing importance of these specialties.

Today, Radiation therapy or Radiotherapy has become the cornerstone of modern cancer management. It is highly effective and widely used for the treatment of cancer ${ }^{28}$. It uses high energy radiation to shrink tumors and kill cancer cells. Xrays, Gamma rays and charged particles are the types of radiation used. The radiation may be delivered by the machine outside body (teletherapy) or it may come from radioactive material placed inside the body near the cancer cells (brachytherapy) ${ }^{29}$. Many types of cancers are treated nowadays by radiation therapy, including, breast, prostate, head and neck and pharyngeal cancers, cancer cells are killed by radiation via damaging their $D_{N A}{ }^{30}$. According to a study, more than half of all cancer patients in developed countries receive radiotherapy to cure the disease, either alone or in combination with other treatment modalities like chemotherapy or surgery ${ }^{31}$. That is why, due to utmost significance of radiotherapy in cancer management, many developed countries like Australia ${ }^{32}$ and Canada $^{33}$ are taking steps to commence teaching of radiation oncology from the undergraduate level. Similarly, Palliative care plays a crucial part in the management of cancer and according to the study conducted in UK; palliative care is potentially beneficial when it is introduced at the time of diagnosis of a serious or life threatening illness like cancer ${ }^{34}$.

\section{CONCLUSIONS}

There is a need to change the perception of palliative care and radiation therapy among medical students. Teaching of radiotherapy should begin early in the undergraduate curriculum of MBBS, it should be mandatory for all the students. Oncology rotations should be constructed where the principles of radiotherapy and palliative care should be conveyed.

Copyright@ 30 Mar, 2014.

\section{REFERENCES}

1. Lawrence TS, Haken RK, Giaccia A. Principles of Radiation Oncology. Cancer: Principles and Practice of Oncology. 8 ed: Lippincott Williams and Wilkins; 2008.

2. Jemal A, Siegel R, Xu J, Ward E. Cancer statistics, 2010. CA: a cancer journal for clinicians. 2010 Sep-Oct;60(5):277-300. PubMed PMID: 20610543.

3. Cancer Incidence and Mortality Worldwide [Internet]. GLOBOCAN. 2008 [cited 04/12/2012]. Available from: http://globocan.iarc.fr.

4. Global burden of disease: 2004 update. WHO Library; 2004.

5. Jemal A, Bray F, Center MM, Ferlay J, Ward E, Forman D. Global cancer statistics. CA: a cancer journal for clinicians. 2011 Mar-Apr;61(2):69-90. PubMed PMID: 21296855.

6. Thun MJ, DeLancey JO, Center MM, Jemal A, Ward EM. The global burden of cancer: priorities for prevention. Carcinogenesis. 2010 Jan;31(1):10010. PubMed PMID: 19934210. Pubmed Central PMCID: 2802672.

7. Connell PP, Hellman S. Advances in radiotherapy and implications for the next century: a historical perspective. Cancer research. 2009 Jan 15;69(2):383-92. PubMed PMID: 19147546.

8. Patel RR, Arthur DW. The emergence of advanced brachytherapy techniques for common malignancies. Hematology/oncology clinics of North America. 2006 Feb;20(1):97-118. PubMed PMID: 16580559.

9. Billings JA, Block S. Palliative care in undergraduate medical education. Status report and future directions. JAMA. 1997 Sep 3;278(9):733-8. PubMed PMID: 9286833.

10. Williams ML, D. R, Macleod M. A systematic review of teaching and learning in palliative care within the medical undergraduate curriculum Medical teacher. 2004 12/2004;26(8):683-90.

11. Anand $P$, Kunnumakkara AB, Sundaram C, Harikumar KB, Tharakan ST, Lai OS, et al. Cancer is 
a preventable disease that requires major lifestyle changes. Pharmaceutical research. 2008 Sep;25(9):2097-116. PubMed PMID: 18626751. Pubmed Central PMCID: 2515569.

12. Baskar R, Yap SP, Chua KL, Itahana K. The diverse and complex roles of radiation on cancer treatment: therapeutic target and genome maintenance. American journal of cancer research. 2012;2(4):372-82. PubMed PMID: 22860229. Pubmed Central PMCID: 3410581

13. Schrijvers D, Joosens E, Vandebroek J, Verhoeven A. The place of death of cancer patients in Antwerp. Palliative medicine. 1998 Mar;12(2):133-4. PubMed PMID: 9616452.

14. Wynder EL, Shigematsu T. Environmental factors of cancer of the colon and rectum. Cancer. 1967 Sep;20(9):1520-61. PubMed PMID: 6038396.

15. Danaei G, Vander Hoorn S, Lopez AD, Murray CJ, Ezzati M, Comparative Risk Assessment collaborating $\mathbf{g}$. Causes of cancer in the world: comparative risk assessment of nine behavioural and environmental risk factors. Lancet. 2005 Nov 19;366(9499):1784-93. PubMed PMID: 16298215.

16. Biswal BM, Zakaria A, Baba AA, Ja'afar $R$. Assessment of knowledge, attitude and exposure to oncology and palliative care in undergraduate medical students. The Medical journal of Malaysia. 2004 Mar;59(1):78-83. PubMed PMID: 15535340

17. Sjoberg J, Halthur C, Kristinsson SY, Landgren O, Nygell UA, Dickman PW, et al. Progress in Hodgkin lymphoma: a population-based study on patients diagnosed in Sweden from 1973-2009. Blood. 2012 Jan 26;119(4):990-6. PubMed PMID: 22147892.

18. Arbyn M, Castellsague $X$, de Sanjose $S$, Bruni L, Saraiya M, Bray $F$, et al. Worldwide burden of cervical cancer in 2008. Annals of oncology : official journal of the European Society for Medical Oncology / ESMO. 2011 Dec;22(12):2675-86. PubMed PMID: 21471563.

19. Field D. Education for palliative care: formal education about death, dying and bereavement in UK medical schools in 1983 and 1994. Medical education. 1995 Nov;29(6):414-9. PubMed PMID: 8594404.

20. Ramakrishnan S, Bolger JJ, Dunn KS, Neal FE, Hancock BW. Undergraduate medical teaching in departments of oncology in the United Kingdom: a questionnaire survey. J Cancer Educ. 1993 Spring;8(1):25-30. PubMed PMID: 8489906.
21. Schug SA, Zech D, Dorr U. Cancer pain management according to WHO analgesic guidelines. Journal of pain and symptom management. 1990 Feb;5(1):27-32. PubMed PMID: 2324558.

22. Macdonald N. Canada and the WHO Cancer Pain Relief Program. Journal of palliative care. 1986 Apr;1(2):31. PubMed PMID: 3450814.

23. Zech DF, Grond S, Lynch J, Hertel D, Lehmann KA. Validation of World Health Organization Guidelines for cancer pain relief: a 10-year prospective study. Pain. 1995 Oct;63(1):65-76. PubMed PMID: 8577492

24. Macauley R, Billings JA. Teaching small groups in palliative care. Journal of palliative medicine. 2011 Jan;14(1):91-5. PubMed PMID: 21244259.

25. Abbas SQ, Muhammad SR, Mubeen SM, Abbas SZ. Awareness of palliative medicine among Pakistani doctors: a survey. JPMA The Journal of the Pakistan Medical Association. 2004 Apr;54(4):195-9. PubMed PMID: 15241997.

26. Sharma DN, Rath GK, Parashar A, Singh P. Survey of undergraduate medical students on their understanding and attitude towards the discipline of radiotherapy. Journal of cancer research and therapeutics. 2010 Jan-Mar;6(1):114. PubMed PMID: 20479540.

27. Wong F, Fairey RN. Radiation oncology--the misunderstood specialty. Journal of the Canadian Association of Radiologists. 1984 Jun;35(2):144-8. PubMed PMID: 6480666.

28. Bobrow M. Radiation-induced disease. Ciba Foundation symposium. 1993;175:182-92; discussion 92-6. PubMed PMID: 8222990.

29. Ionizing radiation. An overview for the occupational health nurse. Agency for Toxic Substances and Disease Registry. AAOHN journal : official journal of the American Association of Occupational Health Nurses. 1997 Apr;45(4):17083. PubMed PMID: 9155267

30. Shiralkar S, Rennie A, Snow M, Galland RB, Lewis $\mathrm{MH}$, Gower-Thomas K. Doctors' knowledge of radiation exposure: questionnaire study. BMJ. 2003 Aug 16;327(7411):371-2. PubMed PMID: 12919987. Pubmed Central PMCID: 175104

31. Janssen $\mathrm{JH}$, Wellens $\mathrm{HJ}$. What do medical students know about in-hospital radiation hazards? Angiology. 1989 Jan;40(1):36-8. PubMed PMID: 2910143. 
32. Tattersall MH, Langlands AO, Smith W, Irwig L. Undergraduate education about cancer. A survey of clinical oncologists and clinicians responsible for cancer teaching in Australian medical schools. European journal of cancer. 1993;29A(11):1639-42. PubMed PMID: 8217375.

33. Steinert Y, McLeod PJ. From novice to informed educator: the teaching scholars program for educators in the health sciences. Academic medicine : journal of the Association of American Medical Colleges. 2006 Nov;81(11):969-74. PubMed PMID: 17065858.

34. Hearn J, Higginson IJ. Do specialist palliative care teams improve outcomes for cancer patients? A systematic literature review. Palliative medicine. 1998 Sep;12(5):317-32. PubMed PMID: 9924595.

\section{It is easier to stay out than get out.}

\section{Mark twain}

